\title{
Intelligent Optimization of Force Tracking Parameters for MR Damper Modelling using Firefly Algorithm
}

\author{
Mat Hussin Ab Talib \\ School of Mechanical \\ Engineering \\ Universiti Teknologi Malaysia \\ 81310 Johor Bahru, Johor, \\ Malaysia \\ mathussin@utm.my
}

\author{
Intan Zaurah Mat Darus \\ School of Mechanical \\ Engineering \\ Universiti Teknologi Malaysia \\ 81310 Johor Bahru, Johor, \\ Malaysia \\ intan@mail.fkm.utm.my
}

\author{
Muhamad Sukri Hadi \\ Faculty of Mechanical \\ Engineering \\ Universiti Teknologi MARA \\ 40450 Shah Alam, Selangor, \\ Malaysia \\ msukrihadi@uitm.edu.my
}

\author{
Hanim Mohd Yatim \\ School of Mechanical \\ Engineering \\ Universiti Teknologi Malaysia \\ 81310 Johor Bahru, Johor, \\ Malaysia \\ hanim.my@utm.my
}

\author{
Nik Mohd Ridzuan Shaharuddin \\ School of Mechanical \\ Engineering \\ Universiti Teknologi Malaysia \\ 81310 Johor Bahru, Johor, \\ Malaysia \\ nmridzuan@utm.my
}

\author{
Annisa Jamali \\ Faculty of Engineering \\ Universiti Malaysia Sarawak \\ Jalan Datuk Nohammad Musa \\ 94300, Kota Samarahan, \\ Sarawak, Malaysia \\ jannisa@unimas.my
}

\begin{abstract}
Magnetorheological (MR) damper system is commonly used to replace the conventional damper in the suspension system due to its low power consumption, fast time response and simple structure. Since inner loop controller is very important in defining the amount of current supplied to the MR damper system, many existing controllers are found not wellstructured in terms of calculating the optimum value of the controller parameter. Poor control design using the conventional method will cause the output current obtained for the MR damper to be unpredictable. To overcome this problem, an intelligent optimization method known as firefly algorithm (FA) was used by this study to optimize the force tracking controller (FTC) parameters as to achieve the exact damping force of MR damper system. The MR damper was first developed using Spencer model and the required voltage input was then provided by the FTC. The controller parameters were tuned using intelligent FA method in order to find the optimum values which would identify the accuracy of the force tracking that followed the MR damping force. The simulation shows that the FTC with FA technique is able to track the desired force better than the heuristic method up to $1.71 \%$ error considering a given desired input force.
\end{abstract}

Keywords: firefly algorithm, force tracking, intelligent optimization, magnetorheological damper, semi active suspension,

\section{INTRODUCTION}

The current demand of vehicle performance has called for many researchers to introduce different types of methods and algorithms to be used in the development of controller device for semi-active suspension system. The magnetorheological (MR) is a smart damper and has received significant attention due to its low power consumption, cheaper price and simpler structure [1;2]. Current research on MR damper system is mainly focusing on the hysteresis modelling of the damper using any parametric or non-parametric modelling approach
$[3 ; 4]$. Bingham model for instance is one of the parametric modelling to represent the MR damper system as studied by Hingane and his team in 2013 [5]. Their research investigated the performance of the vehicle system using Bingham model when it is subjected to the road profile system. The ride and handling performance have shown a good improvement after the passive suspension model intervention. However, important physical elements such as fluid's elastic properties and low shear rates are not well-described which imply that the model might not perform well in describing the optimum behavior of the damper system. Bouc-Wen is another parametric model that describes the MR damper behavior and it was extensively investigated by other researchers [6;7]. This approach has a good potential to predict the characteristics of the MR damper in the post-yield region at the expense of less accuracy. However, the hysteresis behavior of MR damper system using these models does not produce a favorable characteristic in comparison to the experimental responses. To improve this matter, Modified Bouc Wen model or also known as Spencer model was introduced in 1997 [8] and a number of research has also been investigated using the said model recently $[9 ; 10]$. Most of the research done looking at the performance of different parametric modelling show that the Spencer model has a favorable response compared to other models due to its accuracy and ability to track the hysteresis behavior of the model system.

A proper selection of the MR damper model is very crucial in order to design its control system. The amount of current or voltage supplied to the damper needs to be properly conducted using an inner loop controller design structure as it is important to ensure its effectiveness so that the damping constraint can be overcome or resolved. The inner loop controller based on force 